\title{
Effect of KrF excimer laser irradiation on the surface changes and photoelectric properties of $\mathrm{ZnO}$ single crystal
}

\author{
Yong Zeng, Yan Zhao, Yijian Jiang* \\ Institute of Laser Engineering, Beijing University of Technology, Beijing 100124, \\ People's Republic of China
}

\begin{abstract}
In this paper, the effect of $\mathrm{KrF}$ pulsed excimer laser irradiation on the structural, surface morphology, photoluminescence and electrical properties of $\mathrm{ZnO}$ single crystal was investigated. Compared to the as-grown sample, at an irradiation energy density of $257 \mathrm{~mJ} / \mathrm{cm}^{2}$, the $\mathrm{ZnO}$ single crystal exhibits a series of phenomenon: XRD and Raman results show that the crystallization of $\mathrm{ZnO}$ quality change slightly, resistivity is decreased by two orders of magnitude, carrier concentration is increased by one order of magnitude. After laser irradiation, the surface shows some strip lines and no cracks. Formula calculation and simulation results show that the stripes are not caused by surface melting. We speculate that these stripes are caused by the precipitation of $\mathrm{ZnO}$ material inside to the surface. Due to the reduction of oxygen vacancies, UV emission has been enhanced and visible emission has been declined after irradiation. After the laser irradiation, the visible light of $\mathrm{ZnO}$ surface can be regulated. The experimental results show that $\mathrm{KrF}$ laser irradiation could effectively
\end{abstract}

${ }^{*}$ Electronic mail: yjjiang@bjut.edu.cn. 
improve the optical and electrical properties of $\mathrm{ZnO}$ single crystal, which is important for the application of high performance of emitting optoelectronic devices.

Key Words: Excimer laser irradiation; $\mathrm{ZnO}$ single crystal; surface changes; electrical properties; photoluminescence

\section{Introduction}

$\mathrm{ZnO}$ single crystal has been widely studied due to its wide band gap $(3.3 \mathrm{eV})$ and high exciton binding energy $(60 \mathrm{meV})$. Therefore, $\mathrm{ZnO}$ has good prospects in the field of optoelectronic devices. [1], sensors [2] and spintronics [3]. Modern optoelectronic devices typically require a material with an excellent electrical and optical properties. However, as an n-type semiconductor, as-grown $\mathrm{ZnO}$ single crystal normally has many natural defects, such as oxygen vacancies, zinc interstitial etc. [4-7]. These defects are not conducive to the optical and electrical properties of $\mathrm{ZnO}$. As a versatile tool capable of improving functional properties, laser irradiation has attracted considerable attention recently [8-11]. Aoki et al. first reported the $\mathrm{KrF}$ excimer laser induced decrease in UV emission intensity of single crystal $\mathrm{ZnO}$ wafers [12]. Oh et al. studied the improvement in electrical conductivity of single crystal n-type $\mathrm{ZnO}$ after laser irradiation, leading to the formation of a high quality ZnO-based Ohmic contact $[13,14]$. Zhao et al. found that the irradiated $\mathrm{ZnO}$ films exhibited a series of desirable properties: UV emission is distinctly higher, resistivity is decreased by three orders of magnitude [15]. Schneider et al. investigated the structural modifications of $\mathrm{ZnO}$ single crystals that were created by the irradiation with femtosecond 
laser [16]. However, there are few reports about the details of excimer laser irradiation on electrical and photoluminescence properties of $\mathrm{ZnO}$ single crystal. In this paper, $\mathrm{ZnO}$ single crystals were irradiated by a $\mathrm{KrF}$ excimer laser with a wavelength of $248 \mathrm{~nm}$ in the air. The effect of laser irradiation on the photoluminescence, electrical properties and structure of $\mathrm{ZnO}$ single crystals were investigated in detail.

\section{Experiment}

$\mathrm{ZnO}$ single crystals were purchased from MTI Corporation. The samples were grown by hydrothermal method. The quality of the purchased single crystal $\mathrm{ZnO}$ has been shown in our another paper.[17] The size of $\mathrm{ZnO}$ single crystal is $5 \times 5 \times 0.5 \mathrm{~mm}$. $\mathrm{ZnO}$ single crystal was single-sided polishing [1718]. The laser irradiation experiment was performed at room temperature in ambient air by using $\mathrm{KrF}$ excimer laser with a wavelength of $248 \mathrm{~nm}$ and a laser frequency of $1 \mathrm{~Hz}$. The laser energy density was set to be $257 \mathrm{~mJ} / \mathrm{cm}^{2}$. The surface morphology of the irradiated samples were examined by scanning electron microscope (SEM, JEOLJSM 6500F). X-ray diffraction (XRD, D8 ADVANCE) and Raman spectra (HORIBA T64000) were applied to access the structural quality of $\mathrm{ZnO}$. The electrical conductivity of the as-irradiated single crystals was measured by a Hall system (ACCENT HL5500). The photoluminescence spectra were carried out by using the He-Cd laser with a wavelength of $325 \mathrm{~nm}$. All the spectra were recorded at room temperature.

\section{Results and discussions}


$\mathrm{XRD}$ is employed to examine the crystal structure of $\mathrm{ZnO}$ samples. Fig. 1 shows the $\mathrm{XRD}$ of as-grown and as-irradiated $\mathrm{ZnO}$ crystal. The as-irradiated sample was dispose by laser with a pulse count of $\sim 5600$. It distinctly shows that the predominant (002) and (004) $\mathrm{ZnO}$ peaks at $34.4^{\circ}$ and $72.5^{\circ}$, respectively. The dominance of the (002) and (004) peaks indicate that $\mathrm{ZnO}$ single crystal highly textured c-axis-oriented growth and the wurtzite structure. After irradiation, these two peaks exhibit no significant deviation. The full widths at half-maximum (FWHM) of $\mathrm{ZnO}(002)$ peak is $0.08^{\circ}$ and $0.22^{\circ}$ for the as-grown and as-irradiated $\mathrm{ZnO}$, respectively. It means that the crystallization of $\mathrm{ZnO}$ single crystal deteriorated slightly after irradiation. However, due to the small FHWM value, the as-irradiated $\mathrm{ZnO}$ still has a high crystallization.

Fig. 2. (a) shows the Raman spectra of $\mathrm{ZnO}$ single crystals. The as-irradiated $\mathrm{ZnO}$ was dispose by laser with a pulse count of $\sim 5600$. All spectra show three peaks: 99, 333 and $437 \mathrm{~cm}^{-1}$. The peaks at 99 and $437 \mathrm{~cm}^{-1}$ are ascribed to the two non-polar optical phonons modes, $\mathrm{E}_{2}$ (low) and $\mathrm{E}_{2}$ (high), respectively. It is well known that $\mathrm{E}_{2}(\mathrm{low})$ and $\mathrm{E}_{2}(\mathrm{high})$ mode are related to the vibration of $\mathrm{Zn}$ and $\mathrm{O}$ atoms indicative of the wurtzite phase formation, respectively $[18,1919,20]$. The $333 \mathrm{~cm}^{-1}$ peak is due to multi-phonon processes [2021]. These three peaks of $\mathrm{ZnO}$ single crystal show no shift after laser irradiation. Table I shows the full widths at half maximum (FWHM )of as-grown and as-irradiated $\mathrm{ZnO}$. The value of FWHM of $\mathrm{E}_{2}$ (low) and $\mathrm{E}_{2}$ (high) change slightly after irradiation, which means that the crystallization of $\mathrm{ZnO}$ single crystal quality changed little after laser irradiation. This result is consistent with 
the XRD.

Table I The full widths at half maximum (FWHM) of $\mathrm{E}_{2}(\mathrm{low})$ and $\mathrm{E}_{2}$ (high) of as-grown and as-irradiated $\mathrm{ZnO}$ single crystal

\begin{tabular}{|c|c|c|}
\hline & $\mathrm{E}_{2}(\mathrm{low})\left(\mathrm{cm}^{-1}\right)$ & $\mathrm{E}_{2}(\mathrm{high})\left(\mathrm{cm}^{-1}\right)$ \\
\hline as-grown & 2.1 & 6.4 \\
\hline as-irradiated & 2.1 & 6.5 \\
\hline
\end{tabular}

Fig. 3. (a) and (b) show the surface morphology of as-grown and as-irradiated $\mathrm{ZnO}$ single crystal, respectively. It can be seen that the as-grown $\mathrm{ZnO}$ single crystal surface is very smooth. The $\mathrm{ZnO}$ surface shows some strip lines after irradiation. There are no cracks on the as-irradiated sample surface. Khan et al. used $193 \mathrm{~nm}$ excimer laser to irradiate single crystal $\mathrm{ZnO}$ at room temperature. They found that gray to nearly black colored material appeared in the irradiated laser spot. They speculated that the coloration was due to high densities of metallic $\mathrm{Zn}$ nano particles growing on the exposed surface of the crystal [2122]. A constant rate of energy input equal to the pulse energy per unit area $\mathrm{J}\left(\mathrm{J} / \mathrm{cm}^{2}\right)$ divided by the nominal pulse width $\tau$ (20ns) will produce a temperature change at the surface given by [2223]

$$
\Delta T=\frac{2(1-R) J}{k}\left(\frac{\alpha}{\pi \tau}\right)^{\frac{1}{2}}
$$

where $k$ is the thermal conductivity (about $1 \mathrm{~W} \cdot \mathrm{cm}^{-1} \cdot \mathrm{K}^{-1}$, depending on sample treatment [2324]), $\alpha$ is the thermal diffusivity (about $0.08 \mathrm{~cm}^{2} / \mathrm{s}[2425]$ ), and $\mathrm{R}$ is the reflectivity of $\mathrm{ZnO}$ at $248 \mathrm{~nm}$ (about 0.2 ). When the laser fluence is $257 \mathrm{~mJ} / \mathrm{cm}^{2}$, 
where the calculated temperature change from Equation (1) is about $191{ }^{\circ} \mathrm{C}$. Thus, the peak surface temperature during the laser pulse at $257 \mathrm{~mJ} / \mathrm{cm}^{2}$ is about $218{ }^{\circ} \mathrm{C}$. On the other hand, we simulate the temperature changes on the surface of the $\mathrm{ZnO}$ crystal irradiated by laser. Fig. 4 (a) is a schematic diagram of radiation model. In our experiment, we used a $16 \times 16$ lens array to obtain a relative uniform spot. So the distribution of the laser energy on the sample surface was relatively uniform. The heating of material by laser light can be expressed by

$$
\frac{\partial T}{\partial t}=\frac{\alpha}{\rho \cdot C_{p}} I(x, t)+\frac{1}{\rho \cdot C_{p}} \frac{\partial}{\partial x}\left(\kappa \frac{\partial T}{\partial x}\right)
$$

Where $I(x, t)$ is the power density of the laser light at depth $\mathrm{x}$ and time $\mathrm{t}, \mathrm{T}$ is the temperature, and $\rho, C_{p}, \kappa$, and $\alpha$ are the density, specific heat, thermal conductivity, and absorption coefficient of the material, respectively. The heat capacity of $\mathrm{ZnO}$ was $494 \mathrm{~J} \cdot \mathrm{Kg} \cdot \mathrm{K}^{-1}$, the density was $5606 \mathrm{Kg} / \mathrm{m}^{3}$, and the heat conduction coefficient is set to be $\left(\begin{array}{ccc}59.5 & 0 & 0 \\ 0 & 59.5 & 0 \\ 0 & 0 & 120\end{array}\right) \mathrm{W} \cdot \mathrm{m}^{-1} \cdot \mathrm{K}^{-1}$. For simplification, the irradiated sample is defined as uniformly absorbing. Thus, the power density in equation (2) can be described by the Beer-Lambert law. Taking the surface reflectivity of the irradiated material into account by an additional term, the power density $I(x, t)$ can be expressed as

$$
\left.I(x, t)=I_{0}(t) \mathrm{e} \times \mathrm{p}-\alpha \cdot x\right)(1-R)
$$

The output power density of the pulsed excimer laser was modeled by the equation

$$
\left.\left.I(t)=\exp -\exp -\frac{\left(t-t_{c}\right)}{w}\right)-\left(\frac{\left(t-t_{c}\right)}{w}\right)+1\right)
$$


where $t_{c}$ is the time of the pulse peak and $w$ is the pulse width. The best fit between the measured laser pulse and equation (4) is reached with values of $t_{c}=20 \mathrm{~ns}$ and $w=$ $8.96 \mathrm{~nm}$. Since the sample is a rectangular parallelepiped shape, its cross sections are the same. So we only simulated the single cross-sectional temperature distribution at the excimer laser irradiation. Fig. 4 (b) shows the temperature distribution of a cross section. The simulation results show that the peak surface temperature during the laser pulse at $257 \mathrm{~mJ} / \mathrm{cm}^{2}$ is about $209{ }^{\circ} \mathrm{C}$, which is very close to the $218{ }^{\circ} \mathrm{C}$. The melting point of metallic $\mathrm{Zn}$ and $\mathrm{ZnO}$ are 420 and $1975{ }^{\circ} \mathrm{C}$, respectively. It is obviously that $\sim 210^{\circ} \mathrm{C}$ is far lower than the melting point of $\mathrm{Zn}$ and $\mathrm{ZnO}$. So the stripe lines are not caused by surface melting. The photon energy of $\mathrm{KrF}$ excimer laser is $5 \mathrm{eV}$, and the bond energy of $\mathrm{Zn}-\mathrm{O}$ bond is $1.89 \mathrm{eV}$. KrF laser irradiation could cause the dissociation of $\mathrm{Zn}-\mathrm{O}$ bonds. This leads to a large number of oxygen escape from the surface. Therefore, it is possible to cause the precipitation of $\mathrm{ZnO}$ material inside to the surface, forming the stripe lines.

The dependence of the electrical resistivity, carrier mobility, and carrier concentration of the single crystals on the laser pulse count at $257 \mathrm{~mJ} / \mathrm{cm}^{2}$ is shown in Fig. 5. (a). The as-grown $\mathrm{ZnO}$ single crystal had a high resistivity of $\sim 3.0 \times 10^{3} \Omega \cdot \mathrm{cm}$. The results show that the electrical properties are strongly dependent on the laser pulse count. The carrier concentration increases gradually along with the increase of pulse number. When the pulse number was increased to 5600, the carrier concentration tends to be stable for $8.5 \times 10^{14} / \mathrm{cm}^{3}$. The mobility of as-irradiated $\mathrm{ZnO}$ single crystal basically can be maintained at more than $105 \mathrm{~cm}^{2} / \mathrm{V} \times \mathrm{s}$. Fig. 5. (b) 
shows the electrical resistivity of $\mathrm{ZnO}$ single crystal as a function of laser pulse count. The inset exhibits the electrical resistivity of sample on the laser pulse count which is lower than 700. It can be seen that the resistivity increases with the increasing of pulse numbers. The resistivity reaches a maximum value when pulse count is 126 , then decreases with the continued increase of pulse count. When the pulse number reaches 5600 , the resistivity tends to be stable. The value of the stable resistivity is $\sim 60 \Omega \cdot \mathrm{cm}$. After laser irradiation, the resistivity of $\mathrm{ZnO}$ decreased by two orders of magnitude. The intrinsic $\mathrm{ZnO}$ is n-type semiconductor. Oxygen vacancy is the largest number of point defects in $\mathrm{ZnO}$. Usually, a lot of oxygen vacancies will exist in the as-grown $\mathrm{ZnO}$ single crystal. Because the dissociation of $\mathrm{Zn}-\mathrm{O}$ bonds, resulting in the generation of oxygen vacancy. At the beginning of laser irradiation, due to the $\mathrm{Zn}-\mathrm{O}$ bonds is interrupted, a lot of oxygen vacancies are generated in the $\mathrm{ZnO}$ crystal. This leads to the destruction of the $\mathrm{ZnO}$ crystal structure; furthermore, it may cause the increasing of the resistivity. In the process of laser radiation at the same time, the oxygen in the air will enter the $\mathrm{ZnO}$ inside to fill oxygen vacancies. This has resulted in the reduction of oxygen vacancies of $\mathrm{ZnO}$. The decline of the resistivity when the laser count reaches 126 can be ascribe to the reduction of the oxygen vacancies. As the irradiation continued, the number of oxygen vacancies continued to decrease and the resistivity declined. When the oxygen vacancies induced by the laser irradiation and the oxygen vacancies filled by the oxygen in the air achieved dynamic balance, the resistivity is constant. Hall test results show that laser irradiation can significantly improve the electrical properties of $\mathrm{ZnO}$ crystal. 
Fig. 6. (a) shows the photoluminescence (PL) spectra of the as-grown and as-irradiated samples. These spectra all show two PL bands: near band edge (NBE) excitonic UV emission and defect related deep band emission (DBE) in the visible range $[25,2626,27]$. The origin of the $\mathrm{NBE}$ is well known to be excitonic related recombination, the DBE emission is related with intrinsic defects and extrinsic impurities $[27,2828,29]$. It can be seen that when the resistivity with increasing number of pulses have significant change $(\mathrm{N}<2126)$, the intensity of NBE in the as-irradiated sample is lower than which in the as-grown sample; however, the intensity of DBE in the as-irradiated sample is stronger. In the resistivity change flat region $(\mathrm{N}>2626)$, the intensity of NBE in the as-irradiated sample is stronger than which in the as-grown sample; on the other hand, the intensity of DBE in the as-irradiated sample is lower. Some researchers suggest that the change of the $\mathrm{ZnO}$ crystal quality is origin of the UV emission enhancement. Aokiet et al. reported that the UV emission intensity of single crystal $\mathrm{ZnO}$ wafers was decreased by the $\mathrm{KrF}$ excimer laser irradiation, which is attributed to the deterioration in the crystallinity of the $\mathrm{ZnO}$ surface [12]. Wang et al. observed the same results for $\mathrm{Mg}$-doped $\mathrm{GaN}$ thin films after laser irradiation, which is tentatively ascribed to the surface recrystallization under appropriate laser conditions [2930]. However, XRD and Raman results show that the crystallization of $\mathrm{ZnO}$ single quality has not been improved after irradiation. So it is clearly revealed that crystallinity improvement is not the only reason of UV emission enhancement for laser irradiated $\mathrm{ZnO}$ crystal. In our former study, we found that the UV emission intensities of $\mathrm{ZnO}$ films had a 
dependent relationship with resistivity. The UV intensity increases with the decrease in resistivity [15]. As is mentioned in the analysis of electrical properties, the number of oxygen vacancy will increase a lot in the initial irradiation. The crystal quality decline caused UV emission decreases, the increase of oxygen vacancies resulted in enhanced visible light. With the increase of pulse number, the oxygen in the air entering the $\mathrm{ZnO}$ to fill the oxygen vacancy, which results in the improvement of quality of $\mathrm{ZnO}$ crystal. So the $\mathrm{ZnO} \mathrm{UV}$ emission has been enhanced. The visible light emitting weakened. Fig. 6. (b) shows the dependence of the emission peak position on the laser pulse count. It reveals that with the increase of pulse number, the position of the UV peak appeared obvious red-shift. We can use the Expassoc model to fit the data. The fitting equation is shown in Fig. 6. (b). The shift of UV peaks may arise from residual stress and defects in the as-irradiated $\mathrm{ZnO}$ single crystal. Fig. 6. (c) shows the dependence of the intensity ratio of NBE and DBE on the laser pulse count. Compared to as-grown sample, the value of $\mathrm{I}_{\mathrm{UV}} / \mathrm{I}_{\mathrm{DL}}$ is lower in as-irradiated sample when $\mathrm{N}<2126$. As the number of pulse continues to increase, the value of $\mathrm{I}_{U V} / \mathrm{I}_{\mathrm{DL}}$ increased and it is bigger than which in as-grown sample. The results also show that laser irradiation can improve the quality of the photoluminescence of $\mathrm{ZnO}$ crystal.

Laser irradiation can effectively change the stimulated luminescence color of $\mathrm{ZnO}$ single crystal. Fig. 7 shows the different stimulated luminescence color of $\mathrm{ZnO}$ single crystal as a function of laser pulse count. $\mathrm{ZnO}$ single crystal was irradiated by a $325 \mathrm{~nm} \mathrm{He}-\mathrm{Cd}$ laser. It can be seen that as-grown sample under laser irradiation showed green yellow. In the regional resistivity change significantly $(\mathrm{N}<\sim 2300), \mathrm{ZnO}$ 
presents the orange yellow. However, in the area of resistivity changes gently $(\sim 2300<\mathrm{N}<\sim 5600), \mathrm{ZnO}$ appears pale green. In the region of the resistivity basic remain unchanged $(\mathrm{N}>\sim 5600), \mathrm{ZnO}$ shows the dark green. This kind of visible light regulation is very useful for $\mathrm{ZnO}$ applications in photoelectric devices.

In order to further understand the luminescence mechanism of $\mathrm{ZnO}$, the visible PL was divided into peak fitting. Fig. 8. (a), (b), (c) and (d) show the fitting data for VIS emission of $\mathrm{ZnO}$ single crystal at $\mathrm{N}=0,126,2126$ and 3626, respectively. Each spectrum can be fitted using four Gaussian peaks. These four peaks centered at 501, 558, 597 and $656 \mathrm{~nm}$ are ascribed to be $V_{Z n}, V_{O}, O_{i}$ and $O_{i}$, respectively $[30,3131,32]$. We calculated the intensity ratio of yellow orange and green. The results are shown in the Table II. It reveals that $\mathrm{I}_{\text {orange+yellow }} / \mathrm{I}_{\text {green }}$ first increased and then decreased. It means that, with increasing number of pulses, the visible fluorescence from the orange light transition to green light dominated. $\mathrm{ZnO}$ visible light is closely related to the defects. Cause the DBE bands around $550 \mathrm{~nm}$ is attributed to $V_{O}$, so in the case of low pulse number, due to the zinc-O bonds is interrupted, causing a lot of oxygen vacancies is produced inside $\mathrm{ZnO}$. This has resulted in the increase of the proportion of . Therefore, it leads to $\mathrm{ZnO}$ emit orange yellow light. On the other hand, in the process of radiation, the oxygen in the air will enter the $\mathrm{ZnO}$ inside fill oxygen vacancies. This has resulted in the reduction of oxygen vacancies. This could explain the $\mathrm{I}_{\text {orange+yellow }} / \mathrm{I}_{\text {green }}$ decrease. $\mathrm{ZnO}$ appears pale green. As the number of laser pulse continues to increase, the oxygen vacancies produced by laser irradiation and oxygen vacancies filled by the oxygen in 
the air will reach dynamic equilibrium. $\mathrm{ZnO}$ shows the dark green light.

Table II The intensity ratio of yellow orange and green light at different laser pulses.

\begin{tabular}{|c|c|c|c|c|}
\hline Number of laser pulses & 0 & 126 & 2126 & 3626 \\
\hline $\mathrm{I}_{\text {orange+yellow }} / \mathrm{I}_{\text {green }}$ (Intensity ratio) & 1.36 & 1.63 & 1.06 & 0.97 \\
\hline
\end{tabular}

\section{Conclusion}

In conclusion, we investigated the effect of $\mathrm{KrF}$ pulsed excimer laser irradiation on the photoluminescence, electrical properties and structural of $\mathrm{ZnO}$ single crystal under $257 \mathrm{~mJ} / \mathrm{cm}^{2}$. The as-irradiated $\mathrm{ZnO}$ exhibit some peculiarities. XRD and Raman results reveal that the crystallization of as-irradiated sample declined slightly. The surface of the irradiated sample show some strip lines and no cracks. Calculated by the formula and numerical simulation, we conclude that the peak surface temperature during the laser pulse at $257 \mathrm{~mJ} / \mathrm{cm}^{2}$ is about $\sim 210^{\circ} \mathrm{C}$. It is lower than the melting point of zinc and $\mathrm{ZnO}$. We speculate that to a large number of oxygen escape from the surface cause the precipitation of $\mathrm{ZnO}$ material inside to the surface, forming the stripe lines. We speculate that due to a large number of oxygen escape from the surface of $\mathrm{ZnO}$, which lead to the precipitation of internal $\mathrm{ZnO}$ form the stripe lines. $\mathrm{ZnO}$ visible luminescence can be modulated into green yellow, orange yellow, pale green and dark green four colors. The photoluminescence spectra show that laser irradiation can enhance the UV emission and weaken the visible emission with an appropriate pulse count. Hall 
measurement results show that the resistivity is decreased by two orders of magnitude and the carrier concentration is increased by one order of magnitude in the as-irradiate sample. By the laser irradiation, we can regulate the stimulated light color of $\mathrm{ZnO}$ single crystal. The visible light of $\mathrm{ZnO}$ can be modulated to green yellow, orange yellow, pale green and dark green four colors. Optical and electrical results show that $\mathrm{KrF}$ laser irradiation could effectively improve the optical and electrical properties of $\mathrm{ZnO}$ single crystal, which is important for the application of high performance of emitting optoelectronic devices.

\section{Acknowledgements}

This work was supported by the National Science Foundation of China (11374031, 51005005) and Scientific Research Key Program of Beijing Municipal Commission of Education (KZ201210005004).

\section{References}

[1] A.B. Djurisic, A.M.C. Ng and X.Y. Chen, Prog. Quant. Electron 34, 1912010.

[2] P. Ray and V. R. Rao, Appl. Phys. Lett. 102, 0641012013.

[3] R. Saravanan, K. Santhi, N. Sivakumar, V. Narayanan and A. Stephen, Mater. Charact. 67, 102012.

[4] K.M. Wong, S.M. A. Abbas, Y.G. Fang, A. Shaukat and Y. Lei, J. Appl. Phys. 114, 0349012013.

[5] M.M. Chen, Y. Zhu, L.X. Su, Q.L. Zhang, R. Xiang, X.C. Gui, T.Z. Wu, X.Z. Cao, P. Zhang, B.Y. Wang and Z.K. Tang, J. Alloy Compd. 577, 1792013.

[6] K. Kamioka, K. Kuriyama and K. Kushida, Solid State Commun. 188, 122014. 
[7] S.F. O. Mendez, C.R.S. Rodriguez, R.A.G. Valenzuela, F.E. Magana and J.A.M. Aquino, Nanoscale Res. Lett. 9, 1692014

[8] Y. Wu, L.F. Ji, Z.Y. Lin, Y.J. Jiang and T.R. Zhai, Appl. Phys. Lett. 104, 0419062014.

[9] L. Chang, Y.J. Jiang and L.F. Ji, Appl. Phys. Lett. 90. 0825052007.

[10] Y. Liu and Y.J. Jiang, Opt. Express 18, 220412010.

[11] M. Nie, Y. Zhao and Y. Zeng, J. Laser Appl. 26, 0220052014.

[12] T. Aohi, Y. Hatanka, and D. C. Look, Appl. Phys. Lett. 76, 32572000.

[13] M.S. Oh, S.H. Kim, D.K. Hwang, S.J. Park, and T.Y. Seong, Electrochem. Solid-State Lett. 8, G317 2005 .

[14] M.S. Oh, D.K. Hwang, J.H. Lim, Y.S. Choi, and S.J. Park, Appl. Phys.Lett. 91, 0421092007.

[15] Y. Zhao and Y.J. Jiang, J. Appl. Phys. 103, 1149032008.

[16] A. Schneider, D. Wolverson, K. Sebald, C. Hodges, M. Kuball and T. Voss, Appl. Phys. Lett. 102, 2119042013.

[17] S.J. Xie, Y. Zhao and Y.J Jiang, Appl. Surf. Sci.263, 4052012.

[1718] http://www.kjmti.com/products_detail1/\&productId=65.html

[1819] T.A. Harriman, Z. Bi, Q.X. Jia and D.A. Lucca, Appl. Phys. Lett. 103, 1219042013.

[1920] H.K. Yadav, R.S. Katiyar and V. Gupta, Appl. Phys. Lett. 100, 0519062012.

[2021] T.C. Damen, S.P.S. Porto, B. Tell, Phys. Rev. 142, 5701966.

[2122] E.H. Khan, S.C. Langfor, J.T. Dickinson, L.A. Boatner and W.P. Hess, Langmuir 25, 19302009.

[z223] Jaeger, J. C. Aust. J. Sci. Res. A 5, 11952.

[2324] Ü. Özgür, X. Gu, S. Chevtchenko, J. Spradlin, S.J. Cho, H. Morkoc, F.H. Pollak, H.O. Everitt, B. Nemeth, J.E. Nause, J. Electron. Mater. 35, 5502006. 
[2425] X.D. Xu, D. Ma, S.Y. Zhang, A.H. Luo, W. Kiyotaka, Chin. Phys. Lett. 25, 1762008.

[2526] J.G. Simmons, J.V. Foreman, J. Liu and H.O. Everitt, Appl. Phys. Lett. 103, 2011102013.

[2627] T. Shimogaki, K. Okazaki, D. Nakamura, M. Higashihata, T. Asano and T. Okada, Opt. Express

20, 152472012.

[2728] M. Shirazi, M.T. Hosseinnejad, A. Zendehnam, M. Ghoranneviss and G.R. Etaati, J. Alloy

Compd. 602, 1082014.

[2829] Y. Zeng, Y. Zhao and Y.J. Jiang, Appl. Surf. Sci. 301, 3912014.

[2930] X. C. Wang, G. C. Lim, W. Liu, C. B. Soh, and S. J. Chua, Appl. Surf. Sci.252, 20712005.

[3031] J. Liu, Y. Zhao and Y.J. Jiang, Appl. Phys. Lett. 97, 2319072010.

[3132] M. Nie, Y. Zhao, Y. Zeng and Y.J. Jiang, Acta Phys. Sin. 62, 1768012013.

\section{Figure Captions}

Fig. 1. X-ray diffraction of as-grown (black line) and as-irradiated (red line) ZnO single crystal.

Fig. 2. The Raman spectra of as-grown (black line) and as-irradiated (red line) ZnO single crystal.

Fig. 3. SEM images for (a) as-grown and (b) as-irradiated $\mathrm{ZnO}$ single crystal.

Fig. 4. (a) The schematic diagram of radiation model, (b) the simulation of the temperature distribution of a cross section. 
Fig. 5. (a) The dependence of the electrical resistivity, carrier mobility, and carrier concentration of the single crystals on the laser pulse count at $257 \mathrm{~mJ} / \mathrm{cm}^{2}$, (b) the electrical resistivity of $\mathrm{ZnO}$ single crystal as a function of laser pulse count. The inset exhibits the electrical resistivity of sample on the laser pulse count which is lower than 700 .

Fig. 6. (a) The photoluminescence (PL) spectra of the as-grown and as-irradiated samples, (b) the dependence of the emission peak position on the laser pulse count, (c) the dependence of the intensity ratio of NBE and DBE on the laser pulse count.

Fig. 7. The different stimulated luminescence color of $\mathrm{ZnO}$ single crystal as a function of laser pulse count.

Fig. 8. The fitting data for VIS emission of $\mathrm{ZnO}$ single crystal at (a) $\mathrm{N}=0$, (b) 126, (c) 2126 and (d) 3626 , respectively. 


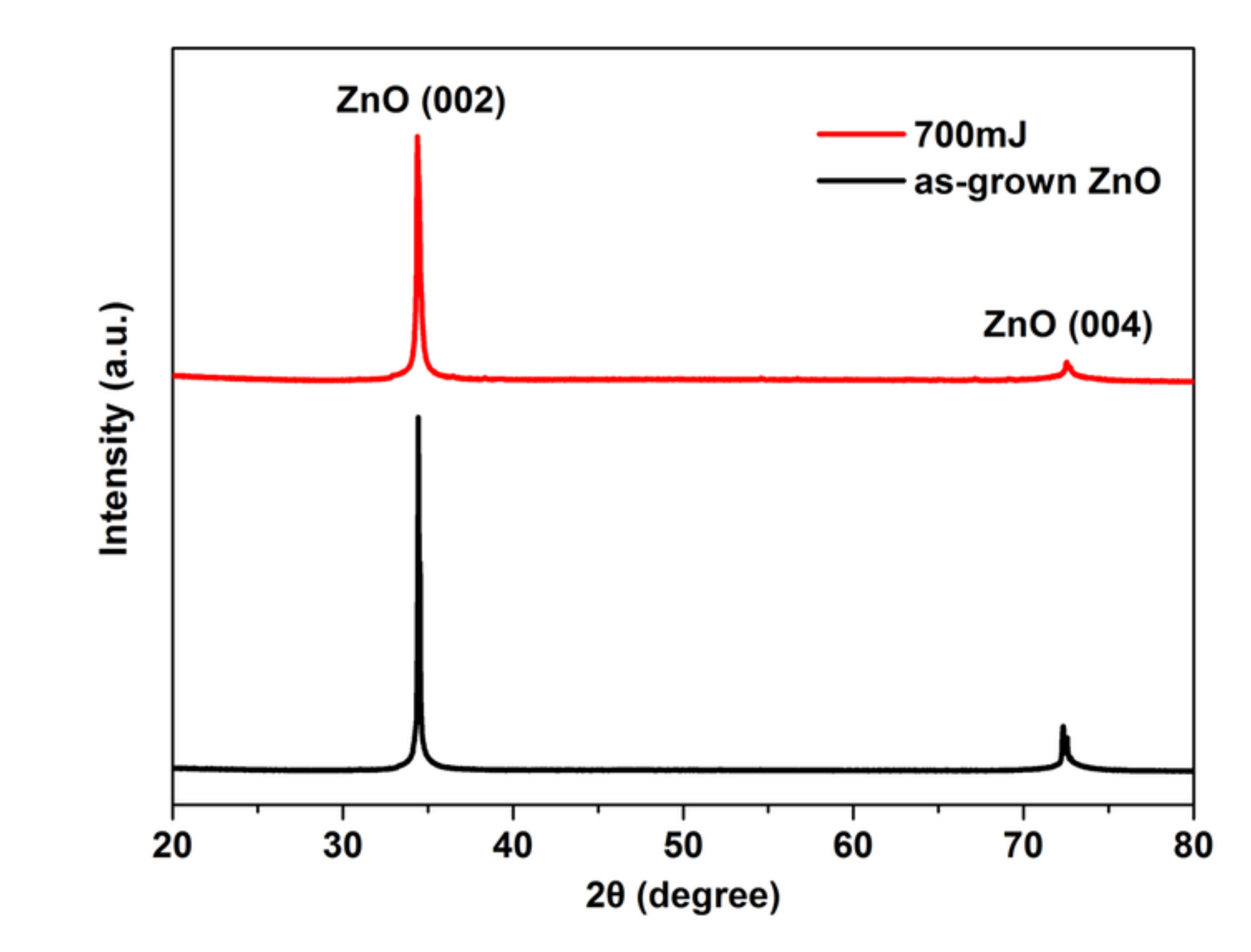




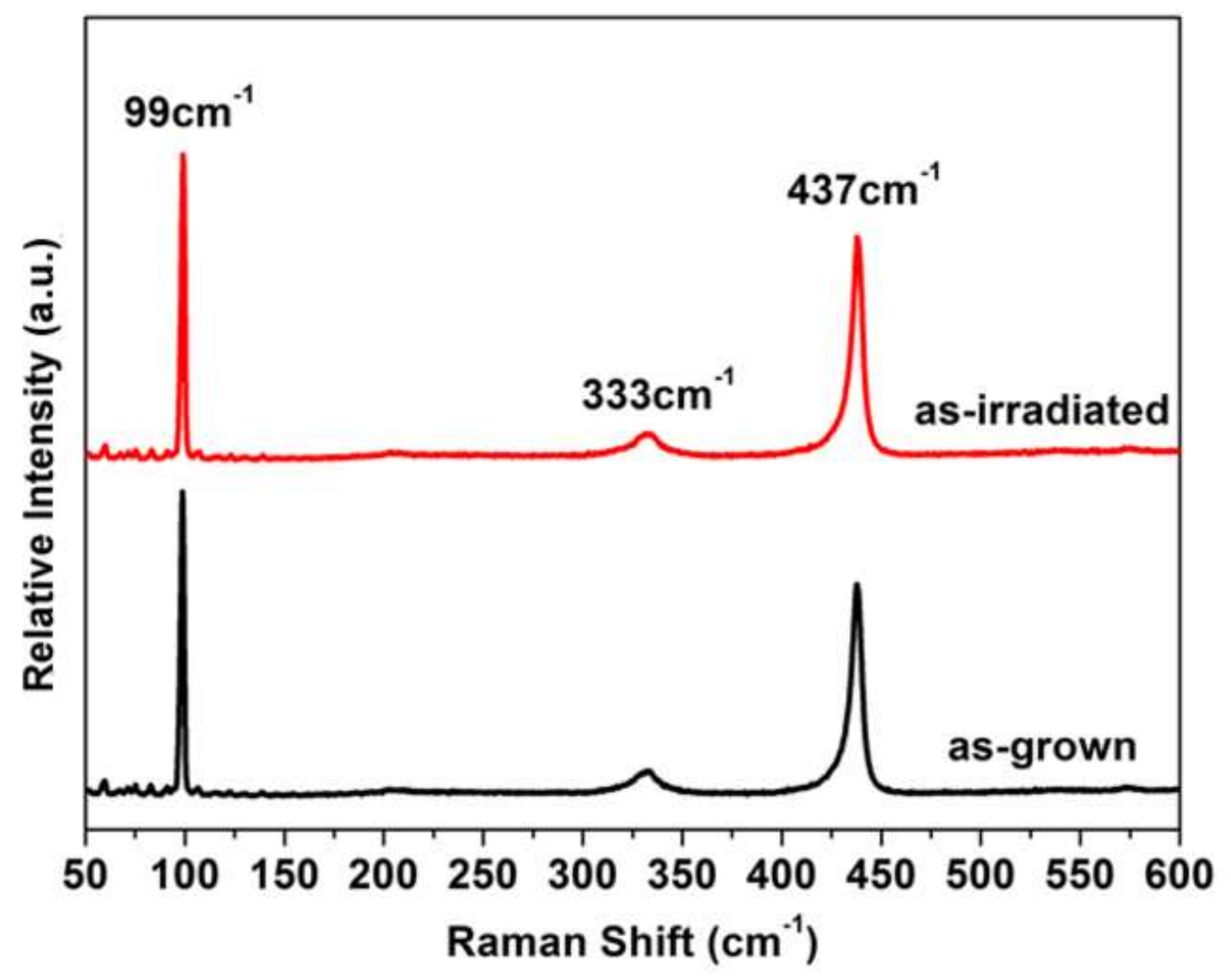




\section{(a)

(b)

$10 \mathrm{~mm}$
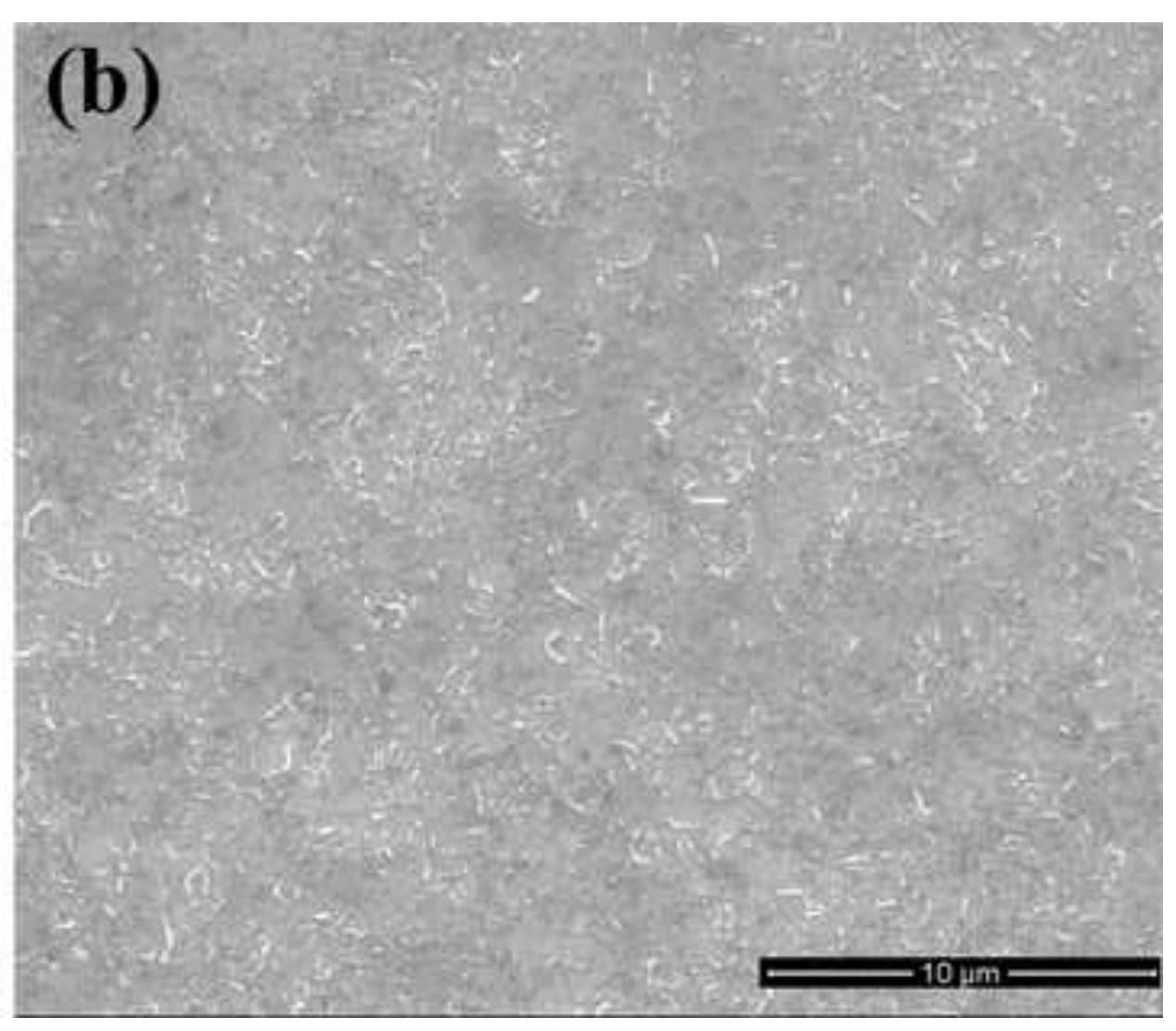
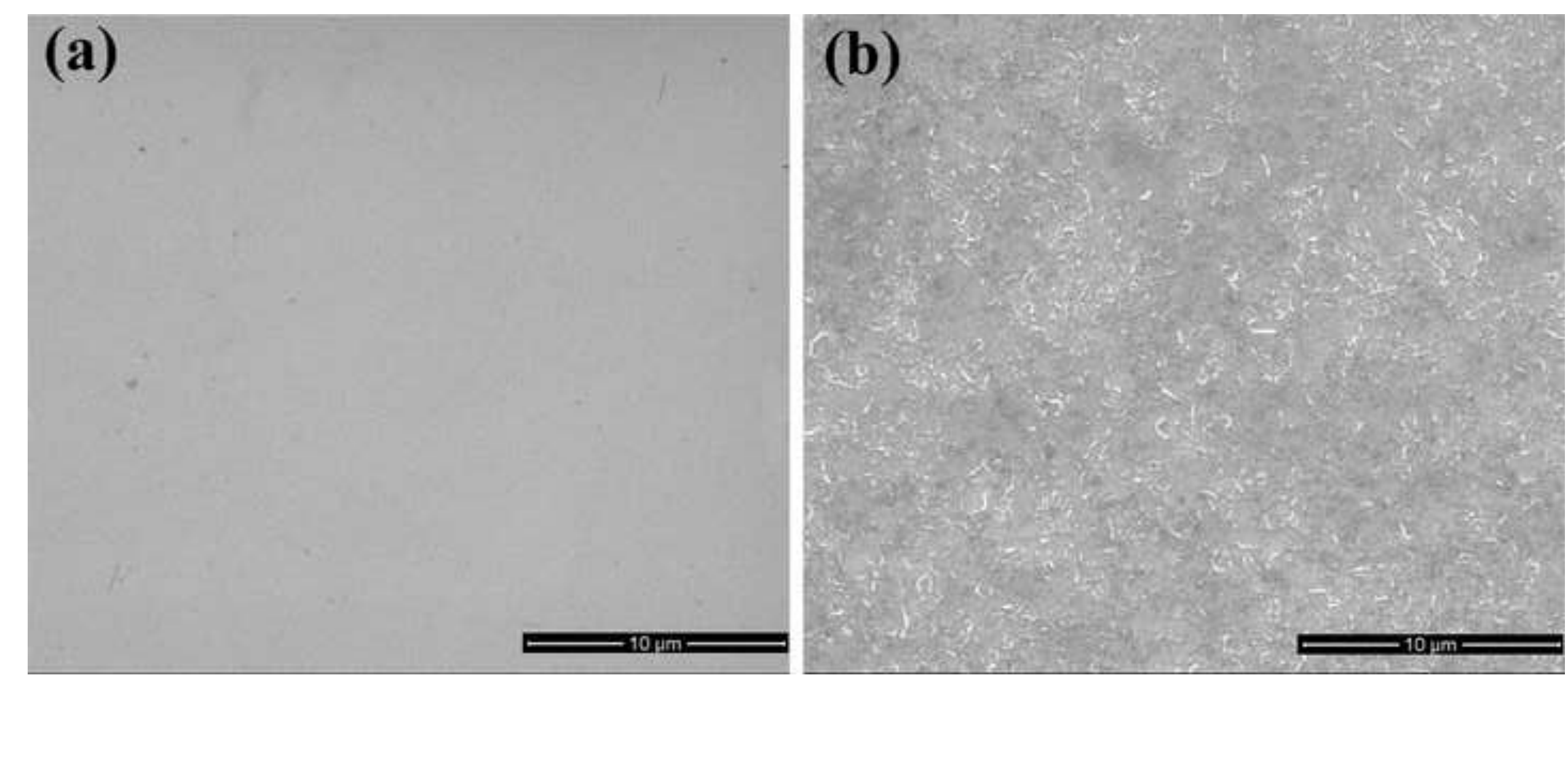
(a)

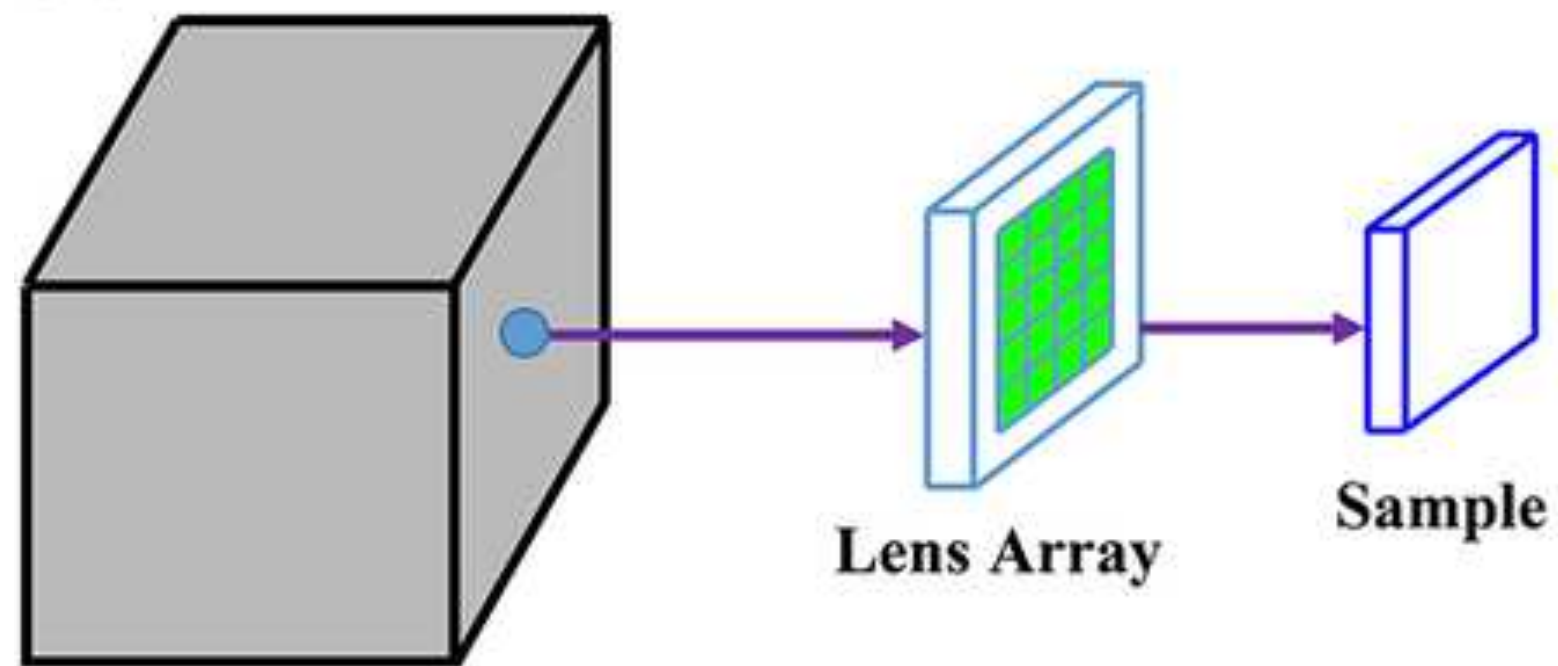

(b)

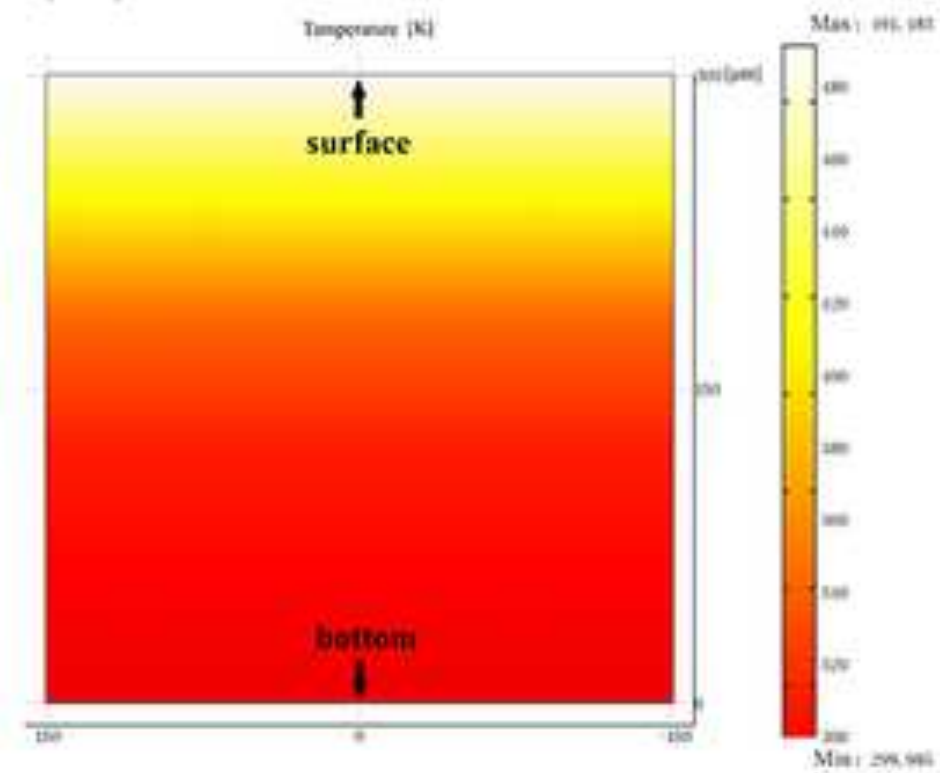

Excimer laser 
(a)

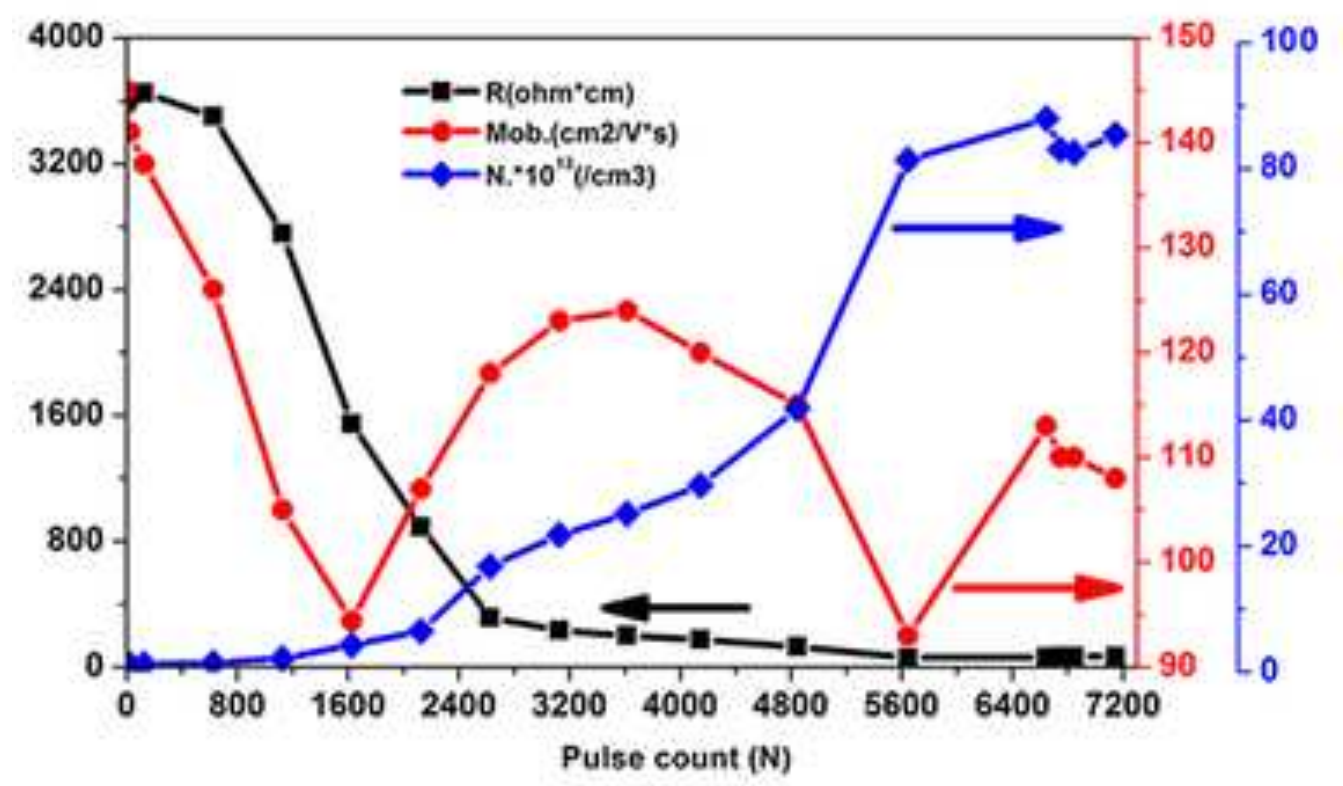

(b)

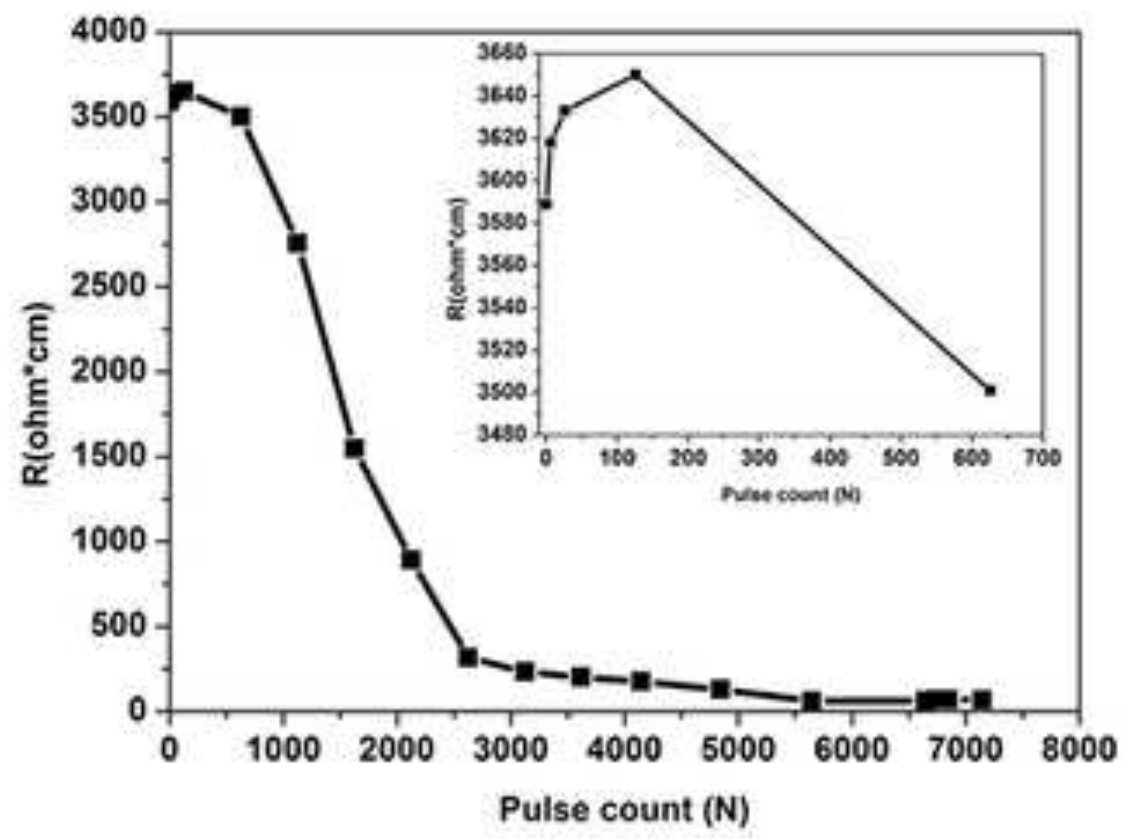


(a)

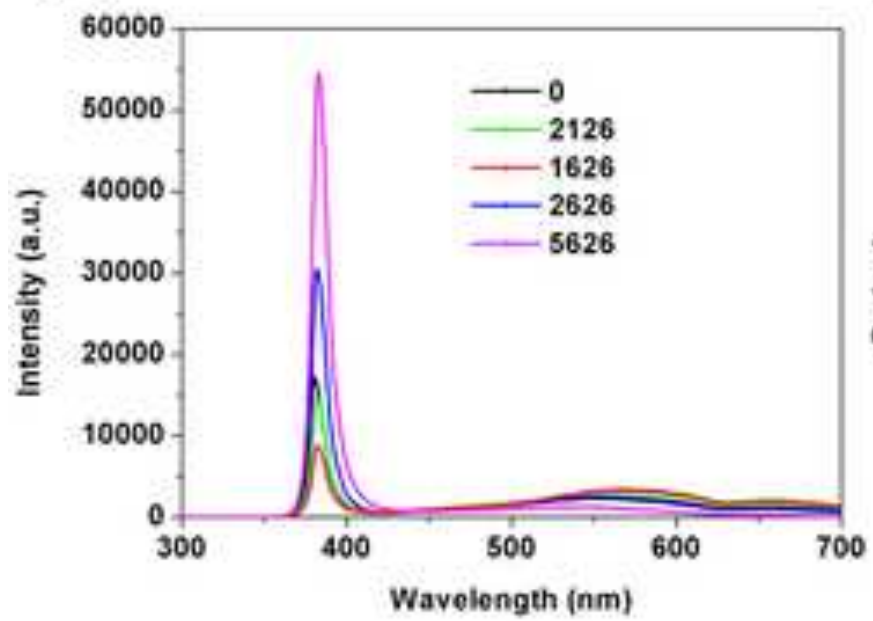

(b)

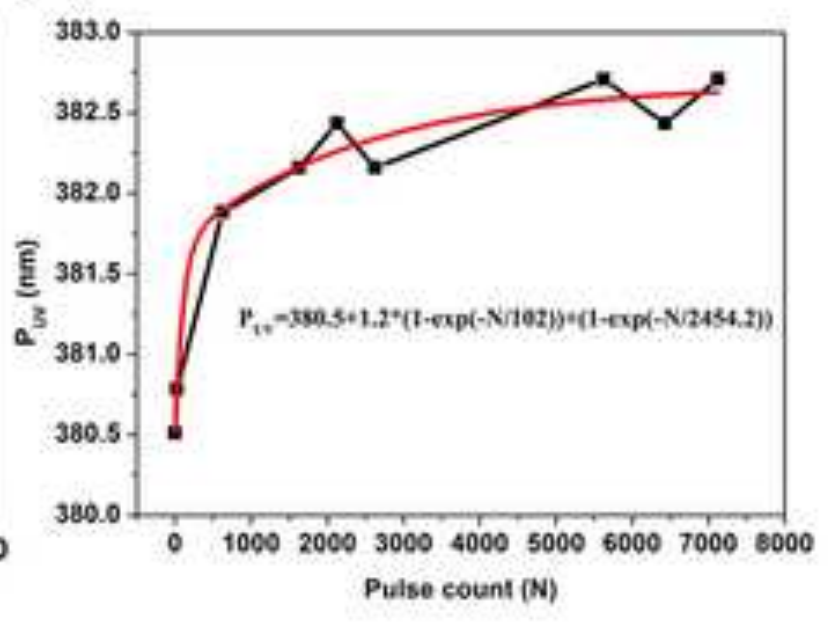

(c)

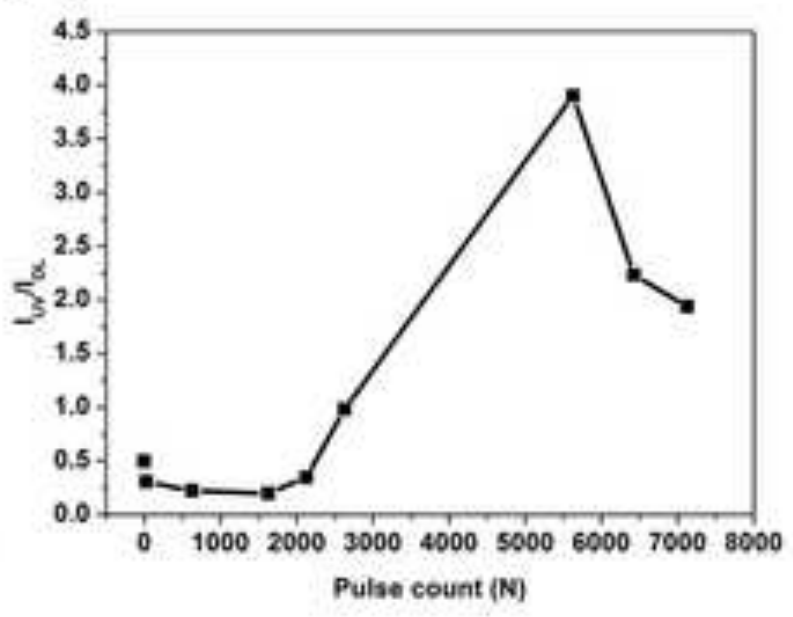




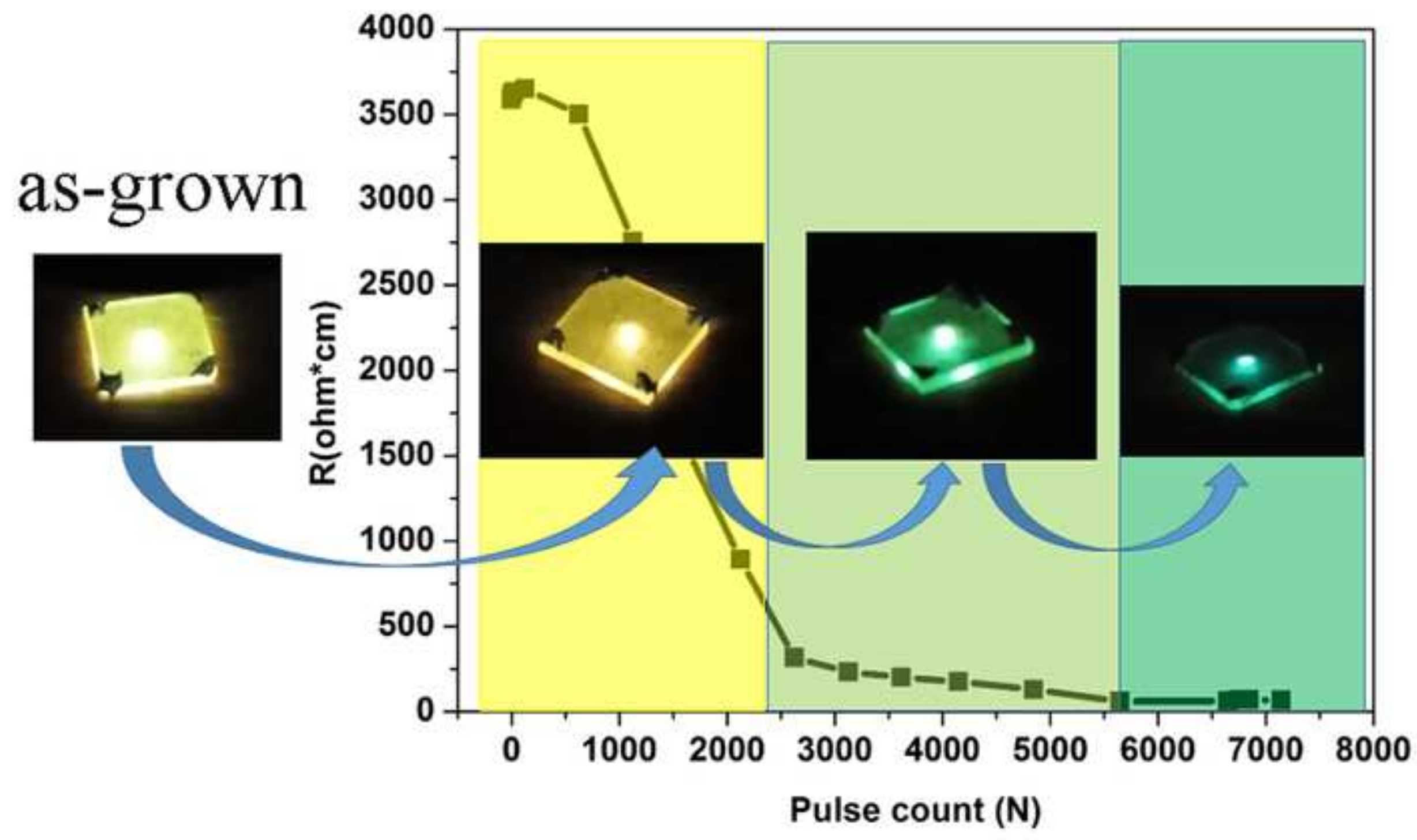


(a)

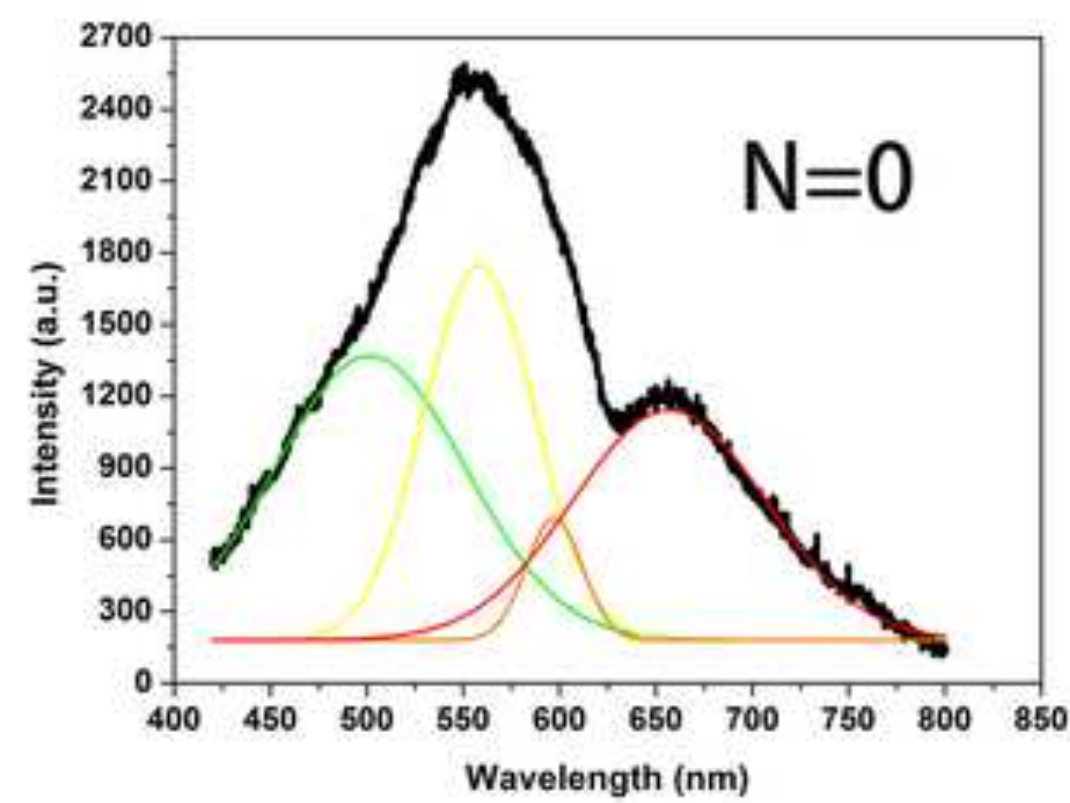

(c)

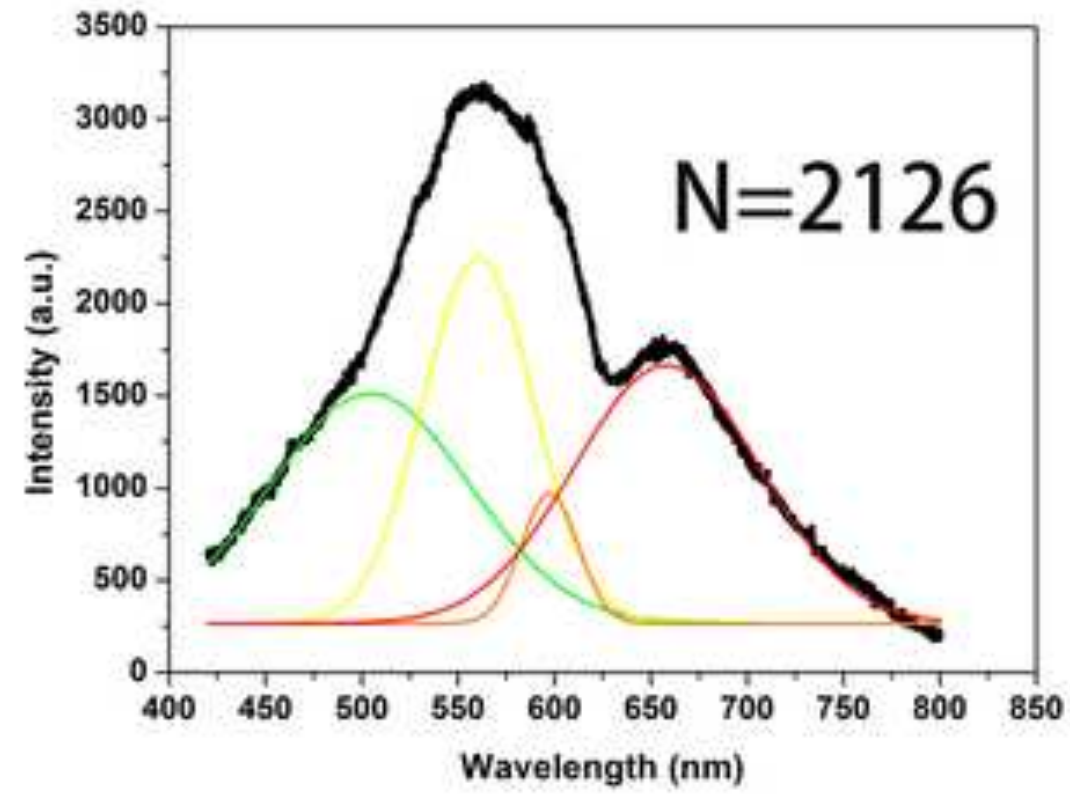

(b)

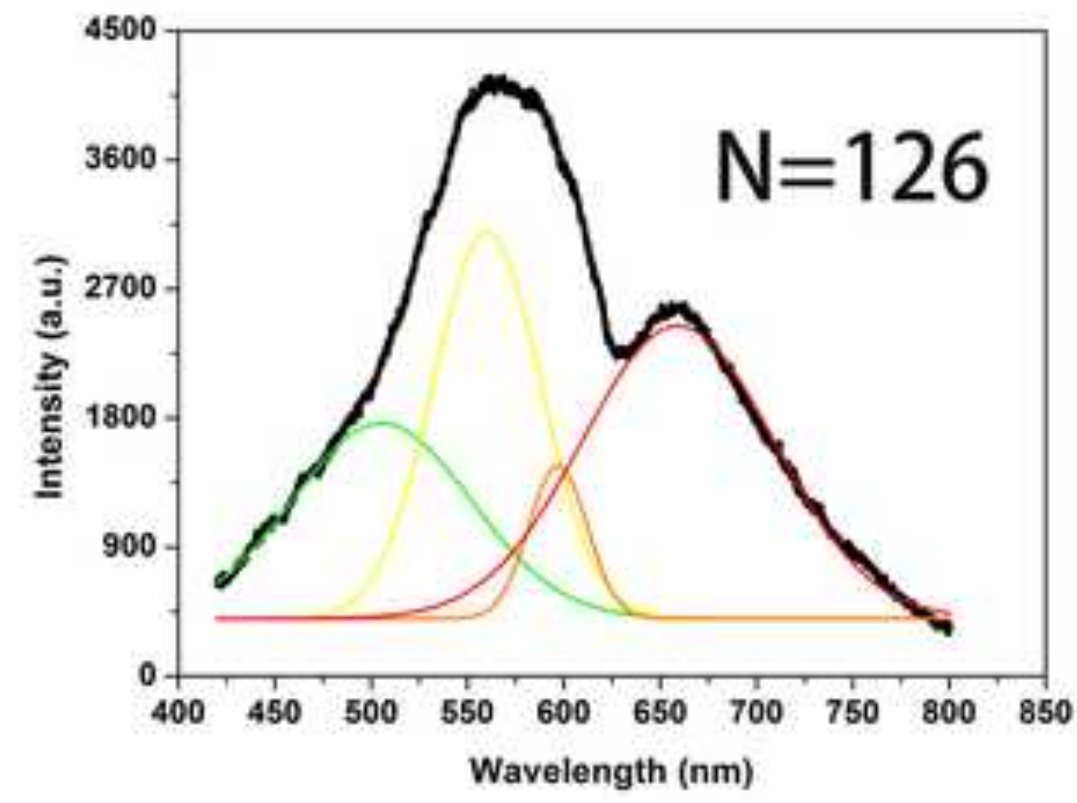

(d)

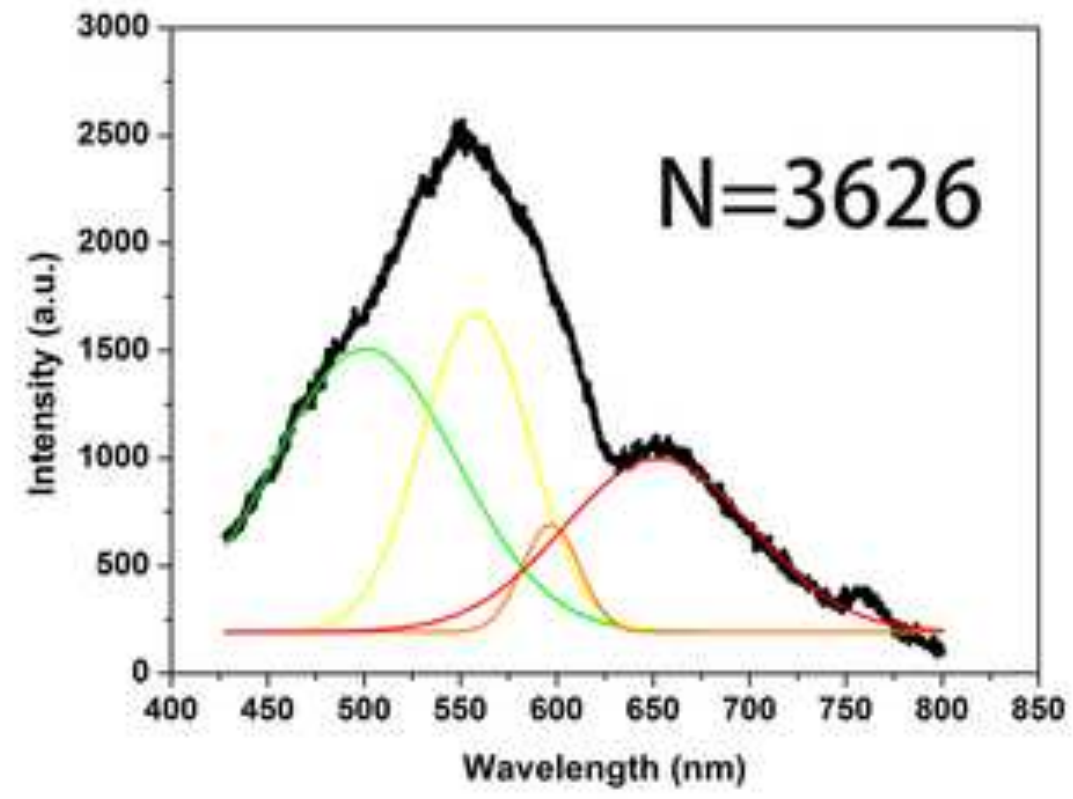

